\title{
The Development of Linguistics and Its Prospects
}

\author{
ZHANG Jie \\ China Youth University of Political Studies, Beijing, China
}

\begin{abstract}
The text makes some researches about the definition of language. It discusses the development of linguistics from the diachronic point of view. Beginning with the definitions and schools of language, it comes to structuralism and linguistics, and the linguistics and literature criticism. The development of linguistics and its relation with other disciplines provide new views for other subjects, and create a new method study. The article mainly shows the panoramic view of linguistics - the definitions, the different schools, and mainly the structuralism. It emphasizes the influences of linguistics on criticism. At the end some outlooks are presented.
\end{abstract}

Keywords: language, linguistics, sketch and development, prospects

\section{Introduction}

Linguistics is the science of language. Traditionally, linguistics is a branch of cultural anthropology, now it becomes more and more independent, and now it is the first level subject among the classification of subjects. Science and technology in the 20th century provide the development of linguistics. With the vigorous development of linguistics, it has formed many branches, such as theoretical linguistics and applied linguistics. To be more specific, phonology, morphology, semantics, pragmatics, sociolinguistics, psycholinguistics, philosophy of language, language and thought, discourse analysis, theory of intercultural communication, translation theories, and the second language acquisition theory, etc. With linguistic research deepening, more and more people write books or articles to make some researches on the topic. The Chinese journal database shows that numerous articles are included. But before 2004, not many articles were published, such as: "western language view of the historical evolution and development of linguistics tend"; "corpus linguistics development prospects"- an overview of the International Conference on corpus linguistics in $2003 ;{ }^{2}$ so on and so forth. In the late development of the linguistics, more articles are about the corpus linguistics. The database shows the top numbers on the corpus linguistics. From a general survey of the development of linguistics, few article mentioned the relationship between linguistics and literature criticism. The article will discuss the historical development of linguistics, its effect on literary criticism, and its prospects.

\section{How to Define Language}

On the issue of defining language, there are a lot of scholars having tried. According to Longman Language

ZHANG Jie, associate professor, master, Department of Foreign Language and Literature, China Youth University of Political Studies.

1 Journal of Northwest University (Philosophy and Social science ed.). (2004/02).

2 Foreign Language World. (2004/04). 
Teaching and Applied Linguistics Language dictionary "Language is human communication system, composed of organized speech system (or its written form), the speech series constitute the larger units, such as morphemes, words, sentences and discourse. One of the most popular linguistic text books in China is Linguistics-A Course Book by HU Zhuang-lin; he defined the language was as a means of oral communication. Different philosophers, linguists with different views on the differences in language showed differences in their knowledge and understanding on language. In the history different masters and scholars gave the definition from their points of view. The following are the general summary of the definitions of language.

(1) Social nature of language. In his Critique of Political Economy, Carl Marx remarked,

Language is a kind of practice. It is a kind of practice both for oneself and for others, and it is a consciousness of existence for oneself and for others. Language is the same as consciousness, just because of the need, and the urgent need to communicate with other people. (Marx, 1955, pp. 147-148)

Marx's words clearly show that the nature of language is need and communication. Firstly, the essence of language is social, then it belongs to the individual. Edward Sapir in the Language also involved in this very important issue - the social features of language. Language is not an instinctive act but a social custom. He said, "Speech is a kind of non-instinctive, acquired 'culture' function" (Sapir, 2002, p. 4). In his the General Linguistics Discourse, Ferdinand Saussure also clearly put forward the "language has its own side, also has its social side, the two cannot be separated" (Saussure, 2001, p. 9). Language is no longer regarded as peripheral to our grasp of the world we live in, but as central to it. Words are not mere vocal labels or communicational adjuncts superimposed upon an already given order of things. They are collective products of social interaction and essential instruments through which human beings constitute and articulate their world. This typical 20th-century view of language has profoundly influenced the developments throughout the whole range of human sciences. It is particularly marked in linguistics, philosophy, psychology, sociology, and anthropology. ${ }^{3}$

As the representative of the late famous philosopher, Ludwig Wittgenstein made some researches about the game nature of language. In his Philosophy of Language, Wittgenstein (2002) mentioned "language as a game, it highlights the following facts, namely language tells but an activity, or is just a part of life" (p. 17). Wittgenstein believed that every word we speak was all part of a language game. For Wittgenstein, language games were similar to an inside joke. You would only get the joke if you were in on the joke. This is similar to language; you will only understand the language being used if you are familiar with the language. That is why Wittgenstein believes that Religious language is meaningful, but only to the religious believers. They are all part of a group that regularly use that language, which has a deep meaning to them. Non-believers would not think that religious language is meaningful, because we are not involved in that "game". Wittgenstein refers to words as "tools" because we use them to build our houses. ${ }^{4}$ This conclusion is similar to that of Sapir. As a necessary condition, it is not only a function of interpersonal communication and understanding, but also the semantic content of the language.

(2) Leonard Bloomfield "stimulus - response" view of language. In the language theory, Bloomfield also discussed the essence of language. He pointed out: To study the phenomenon of language, the necessary step is to

\footnotetext{
3 See https://en.wikipedia.org/wiki/Ferdinand_de_Saussure.

${ }^{4}$ See https://en.wikiversity.org/wiki/Wittgenstein___Language_Games.
} 
observe the language activities (WANG, 2003, p. 197). Only by this can the correct positioning and interpretation of language be achieved. He then defined language as language was human's stimulated response after an actual stimulus. Wang Jian-ping in the Linguistic Philosophy summarized the stimulus response theory as "nonverbal response": $\mathrm{S} \rightarrow \mathrm{R}$. The reaction with words: $\mathrm{S} \rightarrow \mathrm{r}-\mathrm{s} \rightarrow \mathrm{R}$ (ibid).

So many definitions on language undoubtedly showed that language was widely discussed, and the definition changed with time. With the definition of language came the different school of linguistics.

\section{The Schools of Linguistics}

Schools of linguistics are raised and put forward by many linguists and philosophers. From different perspectives on language, linguists and philosophers have different understanding of language. People put the researches into different schools. The Western Linguistics Schools by LIU Run-qing (1995) illustrated the main western linguistic schools (p. 1):

(1) Traditional grammar: Traditional grammar is a framework for the description of the structure of a language. Traditional grammars are commonly used in language education. They may be contrasted with theories of grammar in theoretical linguistics. Traditional grammars seek to describe how particular languages are used, or to teach people to speak or read them. Traditional grammars generally classify words into parts of speech. They describe the patterns for word inflection, and the rules of syntax by which those words are combined into sentences.

(2) Historical linguistics: Historical linguistics, is also called diachronic linguistics. Principal concerns of historical linguistics include: to describe and account for observed changes in particular languages, to reconstruct the pre-history of languages, and to determine their relatedness, grouping them into language families (comparative linguistics), to develop general theories about how and why language changes, to describe the history of speech communities, and to study the history of words, i.e., etymology. ${ }^{5}$

(3) Saussure's linguistics: Saussure's linguistic theory of regarding language as a synchronic and static sign system has turned the historical trend of linguistics and opened up a new pattern of modern linguistics, thus makes linguistics get great achievement in the 20th century. ${ }^{6}$

(4) The Prague School: The Prague School, or Prague linguistic circle, was an influential group of literary critics and linguists in Prague. Its proponents developed methods of structuralist literary analysis and a theory of the standard language and of language cultivation during the years 1928-1939. The linguistic circle was founded in the Café Derby in Prague, which was also where meetings took place during its first years. ${ }^{7}$

(5) Copenhagen School: The Copenhagen School is a term given to "schools" of theory originating in Copenhagen, Denmark. In at least four different scientific disciplines, a theoretical approach originating in Copenhagen has been so influential that they have been dubbed the Copenhagen School. ${ }^{8}$

(6) Structuralism School: In sociology, anthropology, and linguistics, structuralism is the theory that

\footnotetext{
${ }^{5}$ See https://en.wikipedia.org/wiki/Historical_linguistics.

${ }^{6}$ See

http://wenku.baidu.com/link?url=vDg_oALtmR6XWByKjiBssqip2HwgVfZpcNhDQZBW-pffdj4ACRU8_66NOeIL96PBoSgR8

Zu444v1B5gGGo4oJNSfBwc9sWduYvWQ8zMYd63.

7 See https://en.wikipedia.org/wiki/Prague_school.

${ }^{8}$ See https://en.wikipedia.org/wiki/Copenhagen_School.
} 
elements of human culture must be understood in terms of their relationship to a larger, overarching system or structure. It works to uncover the structures that underlie all the things that humans do, think, perceive, and feel. Alternatively, as summarized by philosopher Simon Blackburn, structuralism is the belief that phenomena of human life are not intelligible except through their interrelations. These relations constitute a structure, and behind local variations in the surface phenomena there are constant laws of abstract culture. ${ }^{9}$

(7) London Language School: language as action. Meaning derives from situational context, Phatic communion (as a type of situation) ${ }^{10}$ in which Saussure put forward the general direction of the modern linguistics, the nature of the language, and the language of the task. In his famous works General Linguistics, Saussure discussed the language features, made a distinction between the historical significance of the "langue" and "parole"; "synchronic linguistics and diachronic linguistics", and put forward the theory of Semiotics in language. The first characteristic of language symbols is its arbitrariness. Saussure is also the founder of Semiotics (semiology). Saussure pointed out that the question of language is mainly the question of semiology, and all of our demonstration should obtain meaning from this important fact. To know the essence of language, we must know what common qualities it has with other congener sign system first. He thought that we can imagine there is one science studying the life of sign in social life; we call it semiology.

The "Sapir Wolf hypothesis" profoundly expounds the relationship between language and thinking, which becomes an important part of his theory. This has a certain significance in sociology, anthropology, linguistics, and language teaching.

Bloomfield and the theory of behavior were influenced by the prevailing behavioral psychology. And later by the influence of Bloomfield's language concept, Harris further developed the structuralism and formed a strict positivism which caused into the Post-Bloomfield era.

Hallidy and Functional Linguistics: Systemic linguistics and functional linguistics are also known as systemic functional linguistics. Hallidy is the representative of this school. His representative works are those as Functional Grammar, the interpretation of Language and Meaning. He is unanimously regarded as the master of systematic functional linguistics.

Chomsky and Generative Grammar: He was influenced by structural, and his first book The Syntactic Structure has not gotten rid of the framework of the structuralism. He increasingly felt that the both traditional grammar and structural grammar, could only meet the description of language. They did not answer a fundamental question. He proposed an important language theory. Such as: language ability and language behavior, language acquisition, transformational generative grammar, syntactic structure theory, standard theory, and extended standard theory.

\section{The Structuralism and Post-Structuralism}

With the development of linguistics, the status of linguistics is increasing, which is closely related to other subjects. In particular, the language development has entered a new stage in 50s and 60s in 20th century. The research is sufficient to prove that linguistics has entered a cross disciplinary research, among them the more influential are the structuralism linguistics and post structural linguistics. The term usually means

\footnotetext{
${ }^{9}$ See https://en.wikipedia.org/wiki/Structuralism.

${ }^{10}$ See http://wenku.baidu.com/browse/downloadrec?doc_id=024c23395a8102d276a22f31\&.
} 
"structuralism" in three denotations: modern linguistic theory, modern literary theory, and contemporary French humanistic thought movement (Blockman, 2005, p. 1).

This period has an important influence on both linguistics and literature and art. Perhaps that the process from structuralism to Post structuralism is only one step away or a world of difference. Post structuralism masters are taken mostly as a structuralism masters at the beginning, for example, Lacan was considered as a typical structuralism mater in structuralism heyday. He was later regarded as post structuralism veterans (Danaher, 2002. P. 13). Throughout the 20th century, especially the second half the humanities launched a free thinking game at the domain of structure.

The structural thinkers regarded everything as a game. After the "game" of Wittgenstein, the concept of "game" is considered to be "the game of truth". With the praise of the game is the post structuralism praise of the language. His famous saying: “don't think, just look, see how to play language games (SHANG, 1999, p. 117).

\section{The Effect of Linguistics to Literature Criticism}

With the development of language and philosophy, many philosophers paid attention to language and made language study reaching an unprecedented level in France in 50s and 60s in the 20th century. Therefore, the development promoted literature criticism.

From the above discussion, we can see that the development of language has experienced a process from simple to complex. Since the effect of linguistics theory to other disciplines, there formed a school of a lot of literature criticism. In terms of reading methods, the traditional method of reading is to find the meaning of the author's intention. Traditional reading is "reading" the words. The meaning of deconstruction reading and writing lies in the "extension". Deconstruction reading believes that the meaning of words cannot reach the real meaning; the language cannot totally express the meaning, and the meaning is not a clear concept. The traditional reading is to understand what is said in a book. Books or texts have their own origin, or the central meaning (the author's soul), and purpose (word meaning); the deconstructive reading is to deconstruct the concept of "book". The words are not controlled by speech, soul, or writer's purposes. Words have no origin and clear targets; the traditional reading observes the presences of time, while the destructive reading eliminates the origin and history or words, and also abolishes the boundaries of the past, the present, and the future (SHANG, 1999, pp. 189-190).

\section{The Interdisciplinary Nature of Linguistics}

One of the distinctive features of modern linguistics is the interdisciplinary nature. The development of any new discipline cannot be separated from the other subjects, neither can linguistics develop with the other subjects as reference. First of all, the development of linguistics has led to the development of other related disciplines. It starts with philology to deconstruction for the understanding of the text, especially the all-round development in the 20th century. The prosperity of literary criticism, which is driven by linguistic development, is bound to be more important with the development of the society. Secondly, the development of linguistics also needs other subjects as its theory bases, for example, in terms of social linguistics, social science is needed. Human linguistics uses qualitative research methods from sociology and anthropology. This method is a 
description of linguistic usage. In theoretical linguistics, mathematics and logic are needed for further study in psycholinguistics, psychology, computer linguistics, and computer science.

Within the discipline of linguistics, one of the features is the refinement of the language and the reinforcement of its language branch, that is, usually the important branch of a language is constantly protruding. The popular of one branch may cause the changes in language. For example, the development of the Internet is bound to bring language new vitality, the popular network buzzwords, for example, "pass by", "otaku", "cottage", "Ray", "affordable", "hide and seek", "low carbon", "falsification of graduate employment status", "naked" and "kink", "fishing", "seckill”, "dwelling narrowness", and "ant tribe" are coming into the language continually and actively. Every year the network buzzwords emerge in an endless stream. These linguistic phenomena appear rapidly just because of the network media. The modern network conditions make the language development trend more social and more close to the public. The speed of new language vocabulary transmission is accelerating. This also makes people pay more attention to the development of applied linguistics.

\section{Conclusion}

Although the research of linguistics has made great progress, and the research of language has promoted the research and development of other subjects, especially for the influence of literature criticism. But there are still many problems in the research and development of linguistics. Firstly, the problem exists in individual differences with language learning. Psychology are expected to find the answers to the differences. Secondly, computer translation has made great progress, and it helps the language translation, but there is still many work for scientists to do in aspects of more accurateness of the translation.

For the development of linguistics, the author believes that it has already connected with many social sciences. It has led to many cross researches. But the important prospect for linguistics is that a breakthrough is looking forward to in the present study to bring new energy.

\section{References}

Richard, J. C. (2000). Longman dictionary of language teaching and applied linguistics. Beijing: Foreign Language Teaching and Research Press.

HU. Z. L. (2001). Linguistics - A course book. Beijing: Peking University Press.

Marx, C. (1955). Critique of political economy. Beijing: People's Publishing House.

Sapir, E. (2002). Language. Beijing: The Commercial Press.

Saussure, F. (2001). General linguistics. Beijing: Foreign Language Teaching and Research Press.

Wittgenstein, L. (2002). Philosophy of language. (B. L. CEN, Trans.). Beijing: The Commercial Press.

WANG, J. P. (2003). Linguistic philosophy. Beijing: The Central Committee of the Communist Party of China Press.

LIU, R. Q. (1995).Schools of linguistics. Beijing: Foreign Language Teaching and Research Press.

Blockman, J. M. (2005). Structuralism. (Y. Y. LI, Trans.). Beijing: China Renmin University.

Danaher, J., Schirato, T., \& Webb, J. (2002). Understanding Foucault. (J. LIU, Trans.). Tianjin: Baihua Literature and Art Publishing House.

SHANG, J. (1999). Jacque Derrida. Changsha: Hunan Education Press. 